\title{
Modulation of Burst Firing of Neurons in Nucleus Reticularis of the Thalamus by GluN2C-Containing NMDA Receptors $\$$
}

\author{
Jinxu Liu, ${ }^{1}$ Gajanan P. Shelkar, ${ }^{1}$ Fabao Zhao, Rasmus P. Clausen, and Shashank M. Dravid \\ Department of Pharmacology, Creighton University, Omaha, Nebraska (J.L., G.P.S., S.M.D.); and Department of Drug Design \\ and Pharmacology, Faculty of Health and Medical Sciences, University of Copenhagen, Copenhagen, Denmark (F.Z., R.P.C.)
}

Received March 28, 2019; accepted May 24, 2019

\section{ABSTRACT}

The GluN2C subunit of the NMDA receptor is enriched in the neurons in the nucleus reticularis of the thalamus (nRT), but its role in regulating their function is not well understood. We found that deletion of GluN2C subunit did not affect spike frequency in response to depolarizing current injection or hyperpolarizationinduced rebound burst firing of $\mathrm{nRT}$ neurons. D-Cycloserine or CIQ (GluN2C/GluN2D positive allosteric modulator) did not affect the depolarization-induced spike frequency in $\mathrm{nRT}$ neurons. A newly identified highly potent and efficacious coagonist of GluN1/GluN2C NMDA receptors, AICP $((R)$-2-amino-3-(4(2-ethylphenyl)-1H-indole-2-carboxamido)propanoic acid), was found to reduce the spike frequency and burst firing of $n R T$ neurons in wild type but not GluN2C knockout. This effect was potentially due to facilitation of GluN2C-containing receptors, because inhibition of NMDA receptors by AP5 did not affect spike frequency in $\mathrm{nRT}$ neurons. We evaluated the effect of intracerebroventricular injection of AICP. AICP did not affect basal locomotion or prepulse inhibition but facilitated MK-801induced hyperlocomotion. This effect was observed in wildtype but not in GluN2C knockout mice, demonstrating that AICP produces GluN2C-selective effects in vivo. Using a chemogenetic approach, we examined the role of $n R T$ in this behavioral effect. $\mathrm{G}_{\mathrm{q}}$ - or $\mathrm{G}_{\mathrm{i}}$-coupled DREADDs were selectively expressed in $\mathrm{nRT}$ neurons using Cre-dependent viral vectors and PV-Cre mouse line. We found that similar to AICP effect, activation of $\mathrm{G}_{\mathrm{q}^{-}}$- but not $\mathrm{G}_{\mathrm{i}}$-coupled DREADD facilitated MK-801-induced hyperlocomotion. Together, these results identify a unique role of GluN2C-containing receptors in the regulation of $\mathrm{nRT}$ neurons and suggest GluN2C-selective in vivo targeting of NMDA receptors by AICP.

\section{Introduction}

The nucleus reticularis of the thalamus (nRT) is a sheet of GABAergic neurons that wrap the anterolateral thalamus. It is referred to as "guardian of the gateway" since by strong inhibitory control of the majority of the thalamus it regulates corticothalamic and thalamocortical communication (Crick, 1984; Gentet and Ulrich, 2003; Llinás and Steriade, 2006; Zikopoulos and Barbas, 2006; Lam and Sherman, 2010, 2011). The reciprocal circuits between thalamocortical and nRT neurons are able to intrinsically generate oscillations (von Krosigk et al., 1993; Huguenard, 1998; Huguenard and McCormick, 2007; Sherman, 2007). Owing to these features, the nRT is critical for generation of sleep rhythms, wakefulness, and oscillatory activity that regulates sensorimotor function and attention (Marlinski et al., 2012; Lüthi, 2014;

This work was supported by National Science Foundation [Grant 456818], National Institutes of Health National Institute of Neurologic Disorders and Stroke [Grant NS104705] and National Institute of Mental Health [Grant MH116003].

${ }^{1}$ J.L. and G.P.S. contributed equally to this work

https://doi.org/10.1124/mol.119.116780.

S This article has supplemental material available at molpharm.aspetjournals.org.
Clemente-Perez et al., 2017; Halassa and Kastner, 2017). Functional brain imaging studies in autism patients have revealed abnormal connectivity between thalamus and cortex, supporting a cortical hyperactive state (Nair et al., 2013; Woodward et al., 2017), and this may involve abnormal nRT function. Indeed, recent studies have identified a critical role of $\mathrm{nRT}$ in the regulation of attention in models of autism and neurodevelopmental disorders (Ahrens et al., 2015; Wells et al., 2016; Krol et al., 2018). Moreover, the burst firing of neurons in the nRT leads to cortical seizure like-activity and may underlie occurrence of childhood absence epilepsy (Paz and Huguenard, 2015; ClementePerez et al., 2017).

NMDA receptors are tetrameric channels activated by glycine and glutamate binding to the GluN1 and GluN2 subunit, respectively. The presence of GluN3 subunit instead of GluN2 results in channels activated solely by glycine. There are four GluN2 subtypes, GluN2A through GluN2D. The different subtypes dictate many of the biophysical and pharmacological properties of the NMDA receptors (Traynelis et al., 2010). The GluN2C- and GluN2D-containing receptors differ from GluN2A- and GluN2B-containing receptors by having many contrasting properties as well as a discrete

ABBREVIATIONS: AICP, (R)-2-amino-3-(4-(2-ethylphenyl)-1H-indole-2-carboxamido)propanoic acid; CIQ, (3-Chlorophenyl) [3,4-dihydro-6,7dimethoxy-1-[(4-methoxyphenoxy)methyl]-2(1H)-isoquinolinyl]methanone; CNO, clozapine- $N$-oxide; DCS, D-cycloserine; DREADD, designer receptors exclusively activated by designer drugs; KO, knockout; MK-801, (5S,10R)-(+)-5-Methyl-10,11-dihydro-5H-dibenzo[a,d]cyclohepten5,10 -imine hydrogen maleate; $\mathrm{nRT}$, nucleus reticularis of the thalamus; PB, phosphate buffer; PBT, $0.25 \%$ Triton-X in $0.1 \mathrm{M}$ PB; PPI, prepulse inhibition; PV, parvalbumin; SK, calcium-activated small potassium channel; SOM, somatostatin; WT, wild type. 
expression pattern. The GluN2C/2D-containing receptors have lower sensitivity to $\mathrm{Mg}^{2+}$ blockade, lack desensitization, and have high agonist affinity, but at the same time have low open probability (Traynelis et al., 2010). These features appear to be suited for tonic activity. The neurons in the $\mathrm{nRT}$ regions has been found to be rich in the GluN2C and GluN2D subunits of the NMDA receptors (Watanabe et al., 1992; Buller et al., 1994; Monyer et al., 1994; Lin et al., 1996; Wenzel et al., 1997; Zhang et al., 2012; Astori and Luthi, 2013; Yamasaki et al., 2014; Fernandez et al., 2017; Ravikrishnan et al., 2018; Alsaad et al., 2019). Neurons in nRT have been shown to exhibit NMDA receptor currents that have lower $\mathrm{Mg}^{2+}$ sensitivity, whereas $\mathrm{nRT}$ neurons in GluN2C knockout (KO) mice show a shift to higher sensitivity to $\mathrm{Mg}^{2+}$ blockade (Zhang et al., 2009, 2012; Deleuze and Huguenard, 2016). Despite the known expression of GluN2C in these neurons and their potential tonic activity, their role in regulation of these neurons is unknown. Using knockout models and novel pharmacological tools we addressed the potential role of GluN2C subunit in regulating the burst firing and excitability of $\mathrm{nRT}$ neurons. We modulated the ongoing NMDA receptor activity using a positive allosteric modulator or glycine-site ligands to evaluate the role of the GluN2C subunit. These experiments suggested that only strong facilitation of GluN2C-containing receptors using a novel superagonist, AICP (Jessen et al., 2017), modulated spike frequency or burst firing of $\mathrm{nRT}$ neurons. Importantly increasing function of GluN2C-containing receptors reduced the spike frequency and burst firing of nRT neurons. Intracerebroventricular injection of AICP facilitated MK-801induced hyperlocomotion in wild-type (WT) but not in GluN2C knockout mice, demonstrating in vivo target engagement. Complementary chemogenetic experiments suggest that this in vivo effect of AICP may arise due to modulation of nRT neurons.

\section{Methods}

\section{Animals}

Male C57BL/6N mice were used in this study. Mice were group housed at a constant temperature $\left(22 \pm 1^{\circ} \mathrm{C}\right)$ and a 12-hour light-dark cycle with free access to food and water as previously described (Yadav et al., 2012). GluN2C reporter mice, which also served as GluN2C knockout mice on C57BL/6N background were obtained from Wellcome Trust as previously described (Ravikrishnan et al., 2018). Parvalbumin (PV)-Cre mice (catalog number 008069) were obtained from Jackson Laboratories. Studies were conducted in accordance with the recommendations in the Guide for Care and Use of Laboratory Animals of the National Institutes of Health. All experimental protocols were approved by the Creighton University Institutional Animal Care and Use Committee Policies and Procedures.

\section{Drugs}

DL-AP5 (Alomone Laboratories, Jerusalem, Israel), (+)-CIQ (Brandt Laboratories LLC, Atlanta, GA), and D-cycloserine (DCS) (Sigma-Aldrich, St. Louis, MO) were purchased for electrophysiology experiments. AICP was synthesized as previously described (Urwyler et al., 2009). For in vivo experiments MK-801 (Sigma-Aldrich) and clozapine- $N$-oxide (CNO) (Hello
Bio Inc., Princeton, NJ) were dissolved in saline to the final concentrations and injected by intraperitoneal route. AICP was dissolved in 10\% DMSO + 90\% PEG400 and injected by intracerebroventricular route at a volume of $1 \mu \mathrm{l}$.

\section{Electrophysiology}

Whole-cell electrophysiology was performed as previously described (Gupta et al., 2015, 2016). Mice were decapitated under isoflurane anesthesia, and brains were removed rapidly and placed in ice-cold artificial cerebrospinal fluid (ACSF) of the following composition (in millimolars): $130 \mathrm{NaCl}, 24 \mathrm{NaHCO}_{3}, 3.5 \mathrm{KCl}, 1.25 \mathrm{NaH}_{2} \mathrm{PO}_{4}, 2.4$ $\mathrm{CaCl}_{2}, 2.5 \mathrm{MgCl}_{2}$ and 10 glucose saturated with $95 \% \mathrm{O}_{2} / 5 \%$ $\mathrm{CO}_{2}$. Parasagittal sections (300 $\mu \mathrm{m}$ thick) were prepared using vibrating microtome (VT1200; Leica, Buffalo Grove, IL). Whole-cell patch recordings were obtained from neurons of the $\mathrm{nRT}$ in current-clamp configurations with an Axopatch 200B (Molecular Devices, Sunnyvale, CA). Signal was filtered at $2 \mathrm{kHz}$ and digitized at $10 \mathrm{kHz}$ using an Axon Digidata 1440A analog-to-digital board (Molecular Devices). Whole-cell recordings with a pipette access resistance less than $20 \mathrm{M} \Omega$ and that changed less than $20 \%$ during the duration of recording were included. Glass pipettes with a resistance of 3-5 $\mathrm{M} \Omega$ were filled with a solution containing (in millimolars) $105 \mathrm{~K}$-gluconate, $30 \mathrm{KCl}, 10 \mathrm{HEPES}, 10 \mathrm{Na}_{2}$-phosphocreatine,4 $\mathrm{Na}_{2} \mathrm{ATP}$, and $0.3 \mathrm{Na}_{2}$ GTP ( $\mathrm{pH} 7.2$ ). The current steps were applied for 1 second in 20-pA increments from 0 to $100 \mathrm{pA}$. Spike frequency was calculated in Hertz as a ratio between number of spikes and current step duration. Rebound bursts were induced by applying 1 second $-100 \mathrm{pA}$ current injections at different holding membrane potential from -80 to $-40 \mathrm{mV}$. The number of rebound bursts and the number of spikes in the first rebound burst were measured. The slices were perfused with $100 \mu \mathrm{M}$ DCS, $20 \mu \mathrm{M}$ (+)-CIQ, $100 \mathrm{nM}$ AICP, and $100 \mu \mathrm{M}$ AP5 for 10 minutes after the baseline recordings, followed by the recordings of drug effect. No correction for junction potential was done.

\section{Immunohistochemistry}

Under deep isoflurane anesthesia, mice were transcardially perfused with $4 \%$ PFA in $0.1 \mathrm{M}$ phosphate buffer (PB) and brains were collected and stored overnight in the same fixative at $4^{\circ} \mathrm{C}$. Brains were then transferred sequentially into solutions of $10 \%, 20 \%$, and $30 \%$ sucrose in $0.1 \mathrm{M} \mathrm{PB}$ before freezing in isopentane at -30 to $-40^{\circ} \mathrm{C}$. For immunohistochemistry $20-\mu \mathrm{M}$-thick parasagittal sections were cut using a cryostat (CM 1900; Leica). After washing three times for 5 minutes each with $0.1 \mathrm{M} \mathrm{PB}$, sections were incubated in blocking solution containing $10 \%$ normal goat serum in $0.25 \%$ Triton-X in $0.1 \mathrm{M} \mathrm{PB}$ (PBT) for 1 hour at room temperature. Following blocking, sections were incubated overnight at $4^{\circ} \mathrm{C}$ in the following primary antibodies: chicken anti-GFP (1:1000, A10262; Thermo Fisher Scientific, Waltham, MA), mouse anti-Parvalbumin (PV) (1:5000, PV 235; Swant, Switzerland), and rabbit antisomatostatin 14 (SOM) (1:1000, T-4103.0050; Peninsula Laboratories International, San Carlos, CA) in PBT. The following day, sections were washed six times for 5 minute each in 0.1 M PBT and incubated with the following secondary antibodies: goat anti-chicken antibody conjugated to 
DyLight 488 (1:500, 072-03-24-06; Seracare, Milford, MA), goat anti-mouse antibody conjugated to AlexaFluor 594 (1: 500, A11005; Thermo Fisher Scientific), and goat antirabbit antibody conjugated to AlexaFluor 647 (1:500, A21244; Thermo Fisher Scientific) for 2 hours at room temperature in dark. Sections were then washed six times for 5 minutes each in $0.1 \mathrm{M}$ PBT, mounted on precleaned glass slides, and coverslipped with Fluoromount-G (010001; SouthernBiotech, Birmingham, AL). Images were acquired with Leica TCS SP8 MP scanning confocal microscope.

\section{Cannulation and Viral Injection}

Mice were anesthetized with isoflurane and placed in a stereotaxic frame (Stoelting, Wood Dale, IL). The skull was exposed, a small hole was drilled through the skull, and the 26-gauge stainless steel guide cannula (PlasticOne, Roanoke, VA) was implanted unilaterally above the lateral ventricle at the stereotaxic coordinates (anteroposterior: $-2.2 \mathrm{~mm}$, mediolateral: $+0.8 \mathrm{~mm}$, dorsoventeral: $-2.3 \mathrm{~mm}$ ). The guide cannulae were secured to the skull with stainless steel screws and dental acrylic cement. The animals were allowed 10 days of recovery period before being used for any experiments. For the virus injections, a small hole was drilled above the nRT (anteroposterior: $-0.7 \mathrm{~mm}$, mediolateral: $\pm 1.6 \mathrm{~mm}$, dorsoventral: $-3.5 \mathrm{~mm}$ ). The virus particles AAV2/9-Syn-DIO-hM3D(Gq)-mCherry or AAV2/9-Syn-DIO-hM4D(Gi)-mCherry (Canadian Neurophotonics Platform, Québec, Canada) were injected (100 nl) using a microliter syringe (NanoFil; World Precision Instruments, Sarasota, FL) with 33-gauge beveled needle (NF33BV-2; World Precision Instruments). The injection needle was lowered into the $\mathrm{nRT}$, and virus particles were delivered at a rate of $1 \mathrm{nl} / \mathrm{s}$ using a UMP3 micro-syringe pump (World Precision Instruments). The needle was left in place for an additional 10 minutes at the injection site and thereafter slowly withdrawn over a period of 5 minutes. The incision was sealed with surgical tissue adhesive. After 2 to 3 weeks, these animals were used for the behavioral experiments. Cannula and viral injection locations were verified after the end of behavioral experiments by examining the fixed brain tissue from these animals under light or fluorescent microscope.

\section{Behavior}

Locomotor Activity. Locomotor activity was assessed in a custom-made circular open-field chamber $(27.9 \mathrm{~cm}$ diameter $\times 35.6 \mathrm{~cm}$ wall height) bisected by two photobeams. Locomotion was counted via an automated photobeam break counter, indicating spatial movement when each photobeam was interrupted (Med Associates, Inc., St. Albans, VT). In some experiments, locomotor activity was measured as distance traveled using AnyMaze software.

Prepulse Inhibition. Startle activity was measured using an SR-LAB startle response system (San Diego Instruments, San Diego, CA). The animal enclosure to measure acoustic startle response was a transparent acrylic cylinder (size $12.7 \times 3.81 \mathrm{~cm}$ for mice) fixed on a platform connected to a piezoelectric accelerometer that measures animal movements with an ultra-stable, hermetically sealed motion sensor using a 12-bit resolution. Above the cylinder was a speaker capable of producing noise up to $120 \mathrm{~dB}$ attached to programmable audio controls. The animal enclosure was situated in a sound-attenuating isolation cabinet $(38.1 \times 35.56 \times 45.72 \mathrm{~cm})$ illuminated by a LED (San Diego Instruments). Mice were habituated in the startle chamber for 2 days. For the prepulse inhibition (PPI) experiment, after 5 minutes of acclimation to the startle environment, the response to the startle stimulus alone (120 dB noise, $20 \mathrm{~ms}$ ) and the effect of prepulse stimuli (74, 78 and $84 \mathrm{~dB}$ noise, 20 -ms duration) delivered $100 \mathrm{~ms}$ before the onset of the startle stimulus (120 dB noise) were measured. The acoustic stimuli were superimposed on a $65 \mathrm{~dB}$ background noise. Each PPI session consisted of a total of 54 trials subdivided into four blocks. Blocks 1 and 4 were pulse alone trials $(120 \mathrm{~dB})$ consisting of four stimuli presentation. Blocks 2 and 3 consisted of prepulse and pulse alone trials. A total of 23 trials was presented during each of blocks 2 and 3 with five prepulse trials for each decibel and eight pulse alone trials. Trials within each block were presented in a pseudorandom order and were separated by an intertrial interval ranging from 9 to 21 seconds. Measures of PPI were assessed referencing to the startle stimulus alone presentation as follows:

$\% \mathrm{PPI}=(($ mean startle response to $120 \mathrm{~dB}$ pulse alone mean startle response following a prepulse)/mean startle response to $120 \mathrm{~dB}$ pulse)*100.

Clozapine- $N$-oxide (CNO) was injected intraperitoneally 15 minutes before the beginning of PPI testing, and AICP was injected intracerebroventricularly immediately before PPI testing.

\section{Statistical Analysis}

All data are presented as mean \pm S.E.M. Data were analyzed using unpaired $t$ test, one-way ANOVA or two-way ANOVA with post hoc Bonferroni's multiple comparisons test. Differences were considered significant for $P<0.05$. Prism 6 or 7 (GraphPad Software Inc., San Diego, CA) was used for analysis. All experiments were conducted in at least two independent groups for replication.

\section{Results}

Ablation of GluN2C Subunit Does Not Affect Spike Frequency or Rebound Burst Firing of nRT Neurons. We first examined the expression of GluN2C in nRT neurons. It has been shown that there are at least two major cell populations in this region based on their expression of somatostatin (SOM) or parvalbumin (PV), which differ in their firing properties, efferent projections, and behavioral control (Clemente-Perez et al., 2017). We used a reporter mouse model that we recently described, in which an EGFP reporter cassette is inserted in the intronic region of GRIN2C gene (Ravikrishnan et al., 2018). Thus, EGFP labeling in this model is representative of endogenous GluN2C expression. Using the EGFP reporter mouse model, we found that the majority of EGFP expressing cells in the $\mathrm{nRT}$ are also SOM and PV positive (Fig. 1A), suggesting that $\mathrm{nRT}$ cell population is homogenous for GluN2C expression. We next evaluated the effect of GluN2C deletion on 
A

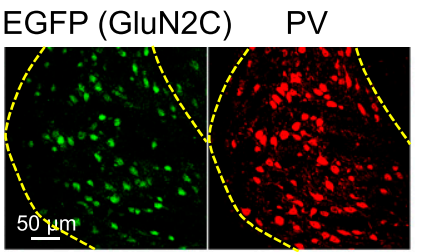

SOM
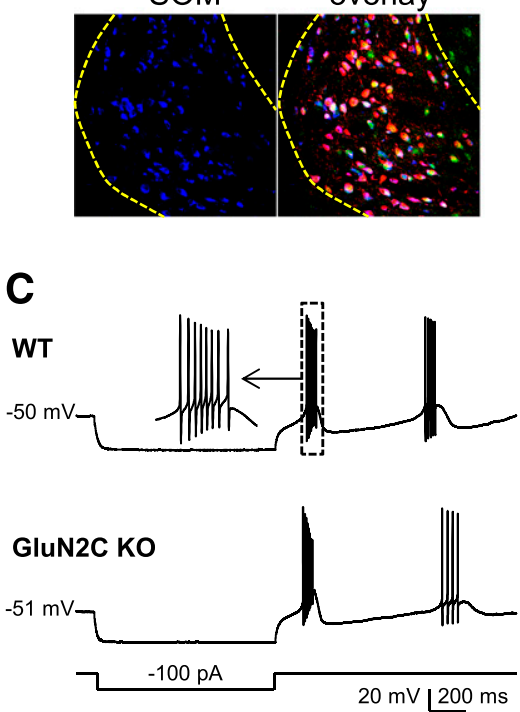

B

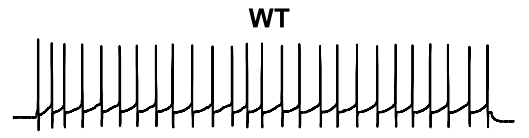

GluN2C KO

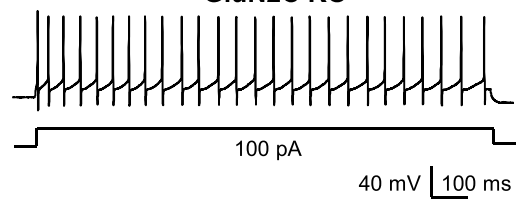

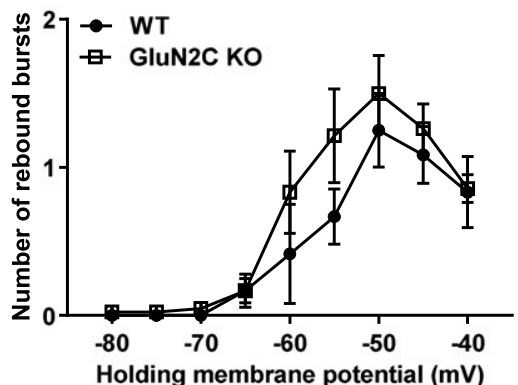

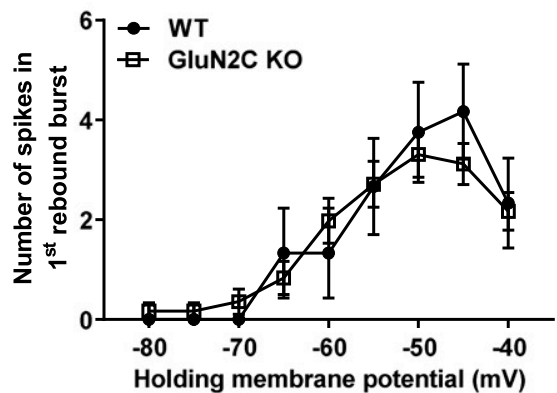

Fig. 1. Deletion of GluN2C subunit does not affect spike frequency/pattern in response to depolarizing current injection or hyperpolarization-induced rebound burst properties of nRT neurons. (A) Labeling of neurons for EGFP (GluN2C), PV, and SOM were evaluated in the nRT. A large number of cells was found to label for all three markers, and only a very small proportion of cells were found to be labeled by one or two markers. (B) Current-clamp recordings were obtained from nRT neurons and effect of depolarizing current injection on spike frequency was evaluated. No change in the spike frequency or pattern was observed in GluN2C knockout $[N=12$ (WT), 43 (GluN2C KO)]. (C) Hyperpolarization-induced rebound burst was examined at different membrane voltages. No change in the number of rebound bursts and the number of spikes in first rebound burst were observed in the GluN2C knockout $[N=12$ (WT), $42($ GluN2C KO)].

properties of nRT neurons. The neurons in nRT generate two distinctive patterns of action potential firing in response to depolarizing and hyperpolarizing current injections known as tonic and burst firing, respectively. Tonic firing involves conventional $\mathrm{Na} / \mathrm{K}$-dependent action potential and provides a measure of excitability of neurons. In contrast, rebound burst firing are also dependent on lowthreshold T-type calcium channel and calcium-activated small potassium channel (SK). Rebound burst firing of nRT neurons produces downstream hyperpolarization and burst firing of thalamic relay neurons accounting for the oscillatory activity (Llinás and Jahnsen, 1982; Jahnsen and Llinas, 1984; Cueni et al., 2008; Clemente-Perez et al., 2017). In current-clamp recordings we first evaluated the effect of GluN2C deletion on the excitability of neurons by measuring the spike frequency in response to current injection (from +20 to $+100 \mathrm{pA}$ ). No significant difference in the spike frequency was observed due to deletion of GluN2C subunit in $\mathrm{nRT}$ neurons (Fig. 1B). In response to current injection of $(-100 \mathrm{pA})$ at various holding potentials in current-clamp recording, burst firing was observed in nRT neurons. No significant effect on the numbers of rebound bursts or the number of spikes in the first rebound burst were observed in GluN2C knockout mice (Fig. 1C). The membrane potential in GluN2C knockout nRT neurons was also not different from WT neurons (Table 1). These results suggest that ablation of GluN2C subunit does not affect basal properties of nRT neurons.

TABLE 1

Effects of DCS, (+)-CIQ, AICP, or AP5 on membrane potential

The effect of D-cycloserine, (+)-CIQ, AICP, and DL-AP5 on membrane potential was evaluated. No significant shift in membrane potential was observed. $N=8$ (DCS), 11 [(+)-CIQ), 4 (AICP-WT), 7 (AICP-GluN2C KO), 11 (AP5-WT), 10 (AP5GluN2C KO)].

\begin{tabular}{lccccr}
\hline & \multicolumn{2}{c}{ WT } & & \multicolumn{2}{c}{ GluN2C KO } \\
\cline { 2 - 3 } \cline { 5 - 6 } & Baseline & Treatments & & Baseline & Treatment \\
\hline & & & $m V$ & \\
$100 \mu \mathrm{M}$ DCS & $-56.72 \pm 2.58$ & $-57.17 \pm 2.94$ & & \\
$20 \mu \mathrm{M}(+)$ )-CIQ & $-50.86 \pm 1.96$ & $-53.84 \pm 2.75$ & & \\
$100 \mathrm{nM}$ AICP & $-64.05 \pm 2.19$ & $-61.95 \pm 6.38$ & & $-62.77 \pm 2.38$ & $-68.44 \pm 3.1$ \\
$100 \mu \mathrm{M}$ AP5 & $-59.04 \pm 2.27$ & $-59.61 \pm 2.38$ & & $-62.29 \pm 3.11$ & $-65 \pm 3.46$ \\
\hline
\end{tabular}


Facilitation of GluN2C-Containing Receptors by AICP Reduces Spike Frequency and Rebound Burst Firing of nRT Neurons. We next tested the effect of pharmacological facilitation of GluN2C-containing receptors on the spike frequency and burst firing of $\mathrm{nRT}$ neurons. Because of lower $\mathrm{Mg}^{2+}$ sensitivity of GluN2Ccontaining receptors, they have been proposed to exhibit tonic activity. Our experimental approach was to facilitate this tonic activity, if any, using either glycine-site agonists or positive allosteric modulators known to increase current amplitude of GluN2C-containing receptors. We first tested the effect of DCS, which is a glycine-site agonist of NMDA receptors with $\sim 1.5$ - to 2 -fold efficacy at GluN1/GluN2C receptors compared with glycine (Sheinin et al., 2001; Dravid et al., 2010). No significant effect of $100 \mu \mathrm{M}$ DCS was observed on spike frequency (Fig. 2A). We then examined the effect of GluN2C/2D positive allosteric modulator (+)-CIQ (Mullasseril et al., 2010; Santangelo Freel et al., 2013), which increases the current response amplitude of GluN2C/GluN2D-containing receptors by approximately two fold, on spike frequency of $n R T$ neurons. No effect of $20 \mu \mathrm{M}$ (+)-CIQ was noted on spike frequency or pattern. Next, we tested the effect of AICP, a recently discovered highly potent NMDA receptor glycinesite agonist, which has $\sim 3.5$-fold higher efficacy at GluN1/ GluN2C receptors compared with glycine (Jessen et al., 2017). Thus, AICP may potentially produce much greater facilitation of tonically active GluN2C-containing receptors. We found that $100 \mathrm{nM}$ AICP significantly reduced the spike frequency of nRT neurons $(80 \mathrm{pA}$ : WT-baseline $29 \pm$ $6.16 \mathrm{~Hz}$ vs. WT- $100 \mathrm{nM}$ AICP $10.17 \pm 5.76 \mathrm{~Hz}, P=0.017$; $100 \mathrm{pA}$ : WT $34.17 \pm 6.01 \mathrm{~Hz}$ vs. WT-100 nM AICP $13 \pm$ $6.63 \mathrm{~Hz}, P=0.005$; Two-way ANOVA with Bonferroni's post hoc test) (Fig. 3A). Importantly, this effect of AICP on spike frequency was GluN2C-dependent and was absent in nRT neurons from GluN2C knockout mice (Fig. 3A). We also tested the effect of NMDA receptor inhibitor DL-AP5 $(100 \mu \mathrm{M})$ on spike frequency and pattern in nRT neurons. We found no effect of DL-AP5 on the spike frequency in wild-type or GluN2C knockout mice (Fig. 3B). Together, the ability of AICP to reduce spike frequency and lack of effect of DL-AP5 suggests that facilitation of GluN2Ccontaining receptors may underlie the reduction of spike frequency of $n R T$ neurons by AICP. We next examined the effect of $100 \mu \mathrm{M}$ DCS and $100 \mathrm{nM}$ AICP on burst firing of nRT neurons. We found that DCS did not affect burst firing or number of spikes in the first rebound burst (Fig. 4A). In contrast, AICP significantly reduced the burst firing $(-50 \mathrm{mV}$ : WT $1.86 \pm 0.46 \mathrm{vs}$. WT- $100 \mathrm{nM}$ AICP $0.43 \pm 0.2, P=0.02$; two-way ANOVA with Bonferroni's post hoc test) and also reduced the number of spikes in first rebound burst $(-50 \mathrm{mV}$ : WT-baseline $5.57 \pm 1.11 \mathrm{vs}$. WT-100 nM AICP $0.43 \pm 0.2, P=0.0001 ;-45 \mathrm{mV}$ : WT $5 \pm$ 1.27 vs. WT- $100 \mathrm{nM}$ AICP $0.43 \pm 0.3, P=0.0008$; two-way ANOVA with Bonferroni's post hoc test) (Fig. 4B). This effect was not observed in GluN2C knockout mice, confirming that AICP effect is mediated via GluN2C-containing receptors. We also examined the effect of pharmacological modulation of NMDA receptors on resting membrane potential of nRT neurons. Previous studies have observed a reduction in resting membrane potential by inhibition of NMDA receptors, which leads to bursting of nRT neurons. However, we found that none of the treatments DCS, (+)CIQ, AICP, or DL-AP5 significantly affected the membrane potential in wild-type nRT neurons (Table 1). In addition, AICP or DL-AP5 did not affect membrane potential in GluN2C knockout mice (Table 1). Together, the genetic knockout and pharmacological experiments demonstrate that basal GluN2C-containing receptor activity may not significantly affect nRT neuron function, but strong facilitation of the basal activity of GluN2C-containing receptors reduces tonic and burst firing of nRT neurons.
A

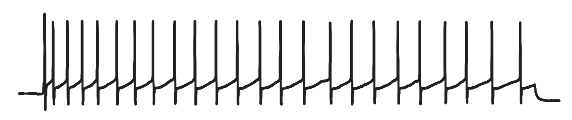

$100 \mu \mathrm{M}$ DCS

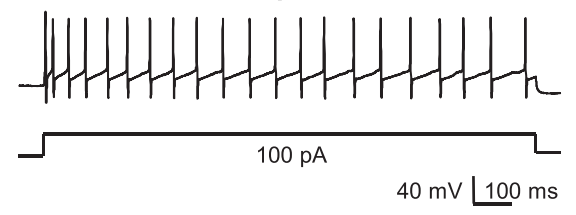

B

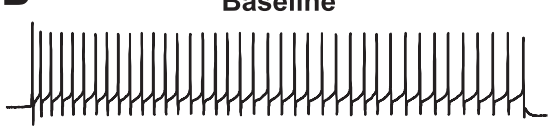

$20 \mu \mathrm{M}(+)-\mathrm{CIQ}$

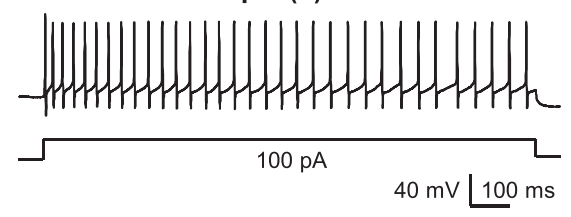

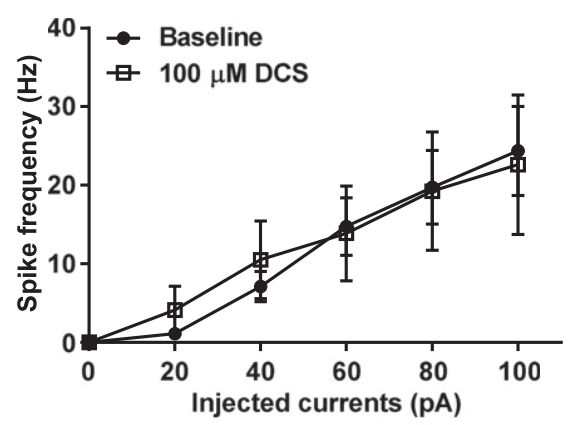

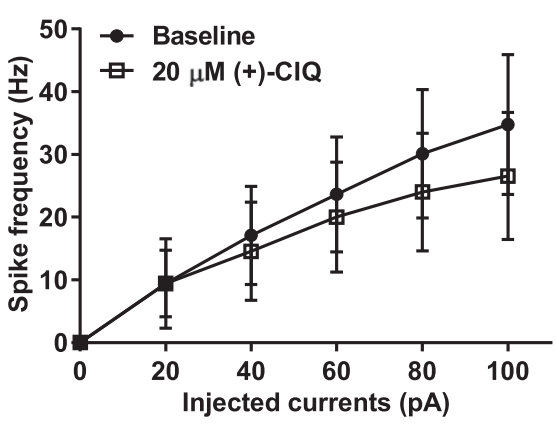

Fig. 2. Effect of modulators GluN2C-containing receptors D-cycloserine and (+)-CIQ on nRT excitability. Current-clamp recordings were obtained from nRT neurons in brain slices prepared from wild-type mice. Application of D-cycloserine $(100 \mu \mathrm{M})(\mathrm{A})$ or $(+)-\mathrm{CIQ}(20 \mu \mathrm{M})(\mathrm{B})$ did not affect current injection-induced spike frequency or pattern $[N=8$ (DCS), 9 (CIQ)]. 

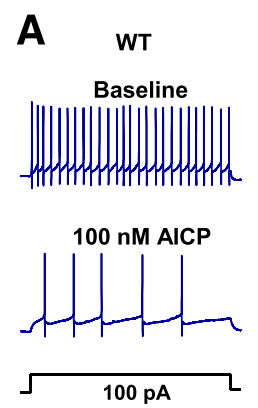

B wT

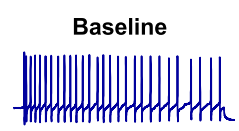

$100 \mu \mathrm{M}$ AP5

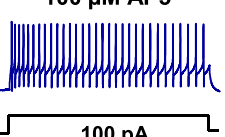

GluN2C KO

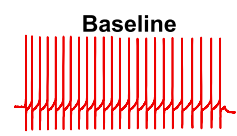

100 nM AICP

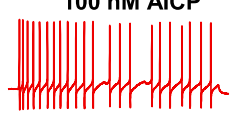

$50 \mathrm{mV} 200 \mathrm{~ms}$

GluN2C KO

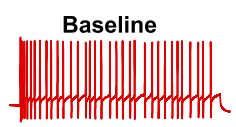

$100 \mu \mathrm{M}$ AP5

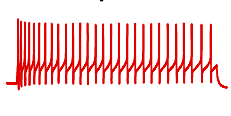

$50 \mathrm{mV} \quad 200 \mathrm{~ms}$

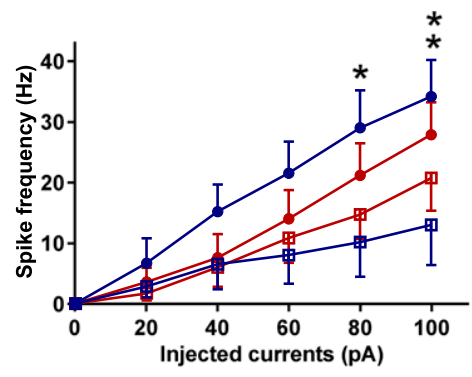

$\rightarrow$ WT-baseline

๑ WT-100 nM AICP

$\rightarrow$ GluN2C KO-baseline

七 GluN2C KO-100 nM AICP

Fig. 3. A novel glycine-site superagonist of GluN1/GluN2C receptors, AICP, reduces the spike frequency of nRT neurons. (A) Bath application of AICP $(100 \mathrm{nM})$ reduced the excitability of nRT neurons in wildtype but not in GluN2C KO [ $N=7$ (WT), 7 (GluN2C KO)], two-way ANOVA with Bonferroni post hoc test $* P<0.05$; **P $<0.01$. (B) No effect of AP5 (100 $\mu \mathrm{M})$ on spike frequency in wild type or GluN2C KO [N=10 (WT), 9 (GluN2C KO)].

Intracerebroventricular Injection of AICP Facilitates MK-801-Induced Hyperlocomotion Potentially via Effect on nRT Neurons. The ability to selectively modulate $\mathrm{nRT}$ function may have therapeutic implications for certain neuropsychiatric and neurologic disorders. Thus, we conducted a set of experiments to evaluate whether AICP may produce in vivo effects mediated by GluN2C-containing receptors in the nRT. We tested for effects of AICP on simple sensorimotor behaviors that are known to be modulated by NMDA receptor function and thalamic activity. Intracerebroventricular injection of AICP alone did not produce a significant effect on locomotor activity (Supplemental Fig. 1B). AICP also did not modulate prepulse inhibition (PPI) or startle amplitude (Supplemental Fig. 1C),
A

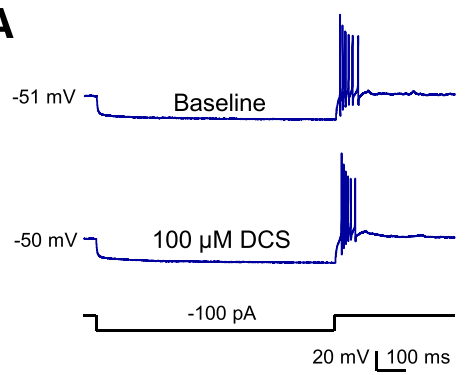

$\mathbf{B}$

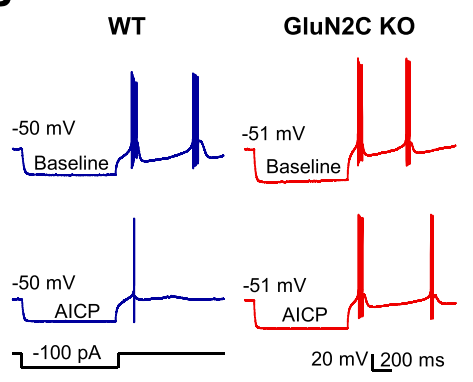

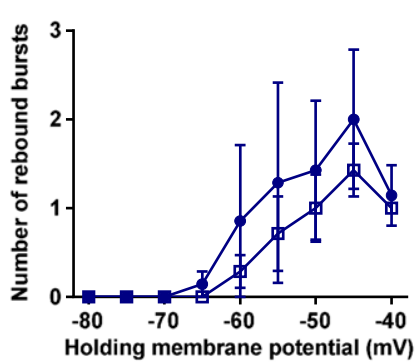
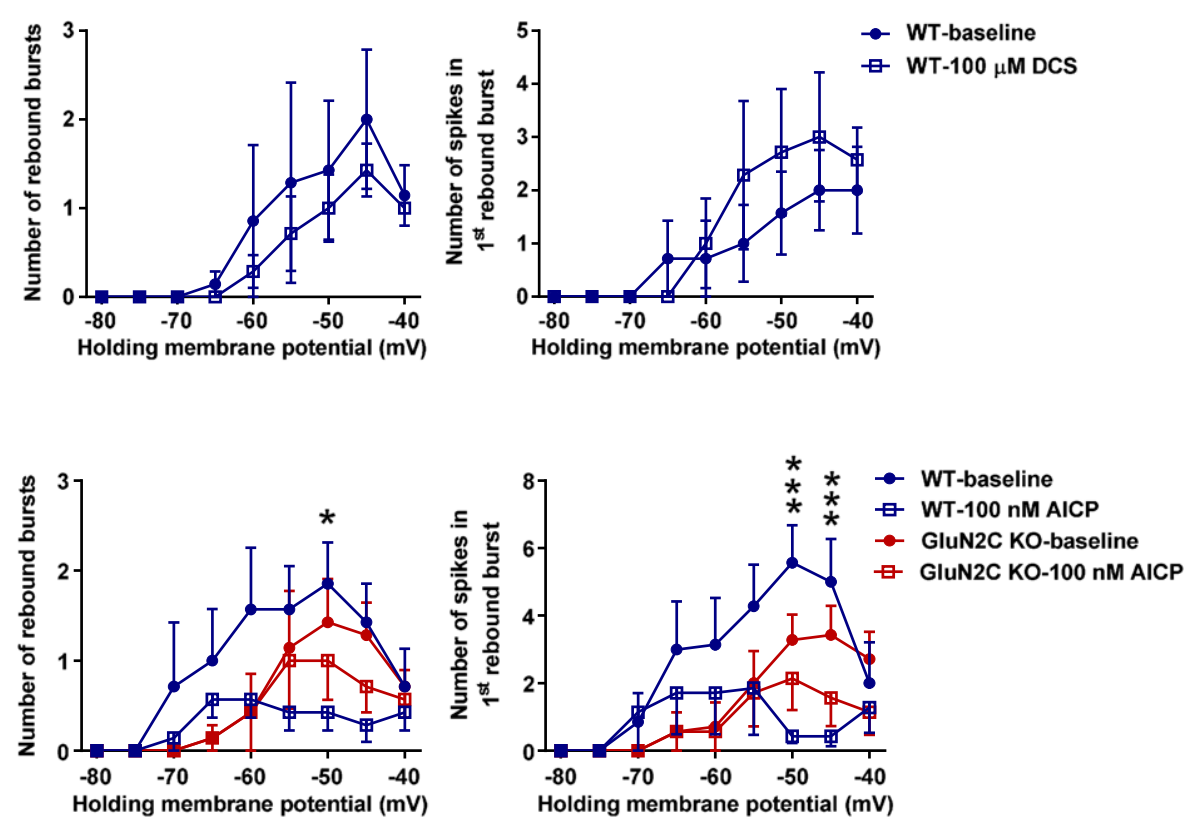

Fig. 4. Glycine-site superagonist of GluN1/GluN2C receptors AICP reduces hyperpolarization-induced rebound burst firing of nRT neurons. (A) Bath application of D-cycloserine did not have a significant effect on the rebound burst firing of nRT neurons $(N=7)$. (B) AICP reduced the rebound burst firing of nRT neurons $(-50 \mathrm{mV}$ : WT $1.86 \pm 0.46 \mathrm{vs}$. WT-100 nM AICP $0.43 \pm 0.2, * P=0.02$; two-way ANOVA with Bonferroni's post hoc test) and also reduced the number of spikes in first rebound burst [ $(-50 \mathrm{mV}$ : WT-baseline $5.57 \pm 1.11 \mathrm{vs}$. WT- $100 \mathrm{nM}$ AICP $0.43 \pm 0.2$, *** $P=0.0001 ;-45 \mathrm{mV}$ : WT $5 \pm 1.27 \mathrm{vs}$. WT- $100 \mathrm{nM}$ AICP $0.43 \pm 0.3, * * * P=0.0008$; two-way ANOVA with Bonferroni's post hoc test]. This effect of AICP was absent in GluN2C KO $[N=7(\mathrm{WT}), 7(\mathrm{GluN} 2 \mathrm{C} \mathrm{KO})]$. 
suggesting minimal effect of GluN2C-containing receptors under resting conditions in these experimental paradigms. Antagonism of NMDA receptors by channel blockers produces hyperlocomotion. Because of the potential tonic activity of GluN2C-containing receptors, some of the effects of NMDA receptor ion channel blockers have been proposed to be mediated by GluN2C-containing receptors (Khlestova et al., 2016). Thus, we further tested whether AICP may modulate NMDA receptor ion channel blocker effects, potentially by facilitating channel blockade. Based on our previous observations, we used a subthreshold dose of NMDA receptor ion channel blocker, MK-801, which alone does not produce a significant increase in locomotor activity. We found that intracerebroventricualar injection of AICP facilitated locomotion in response to a subthreshold intraperitoneal dose of MK-801 (one-way ANOVA, $P=0.0033$, post hoc Bonferroni test vehicle-MK-801 vs. AICP-MK-801 $P=0.0164$; Fig. 5B). Importantly, this effect was observed only in wild type but not in GluN2C knockout (Fig. 5C), suggesting this effect was GluN2C dependent.

To evaluate whether this behavioral effect of AICP on MK-801-induced locomotor activity may arise due to modulation of nRT neurons, we used a chemogenetic approach. DREADD (designer receptors exclusively activated by designer drugs) technique utilizes expression of G-proteincoupled receptors, which are insensitive to endogenous

A
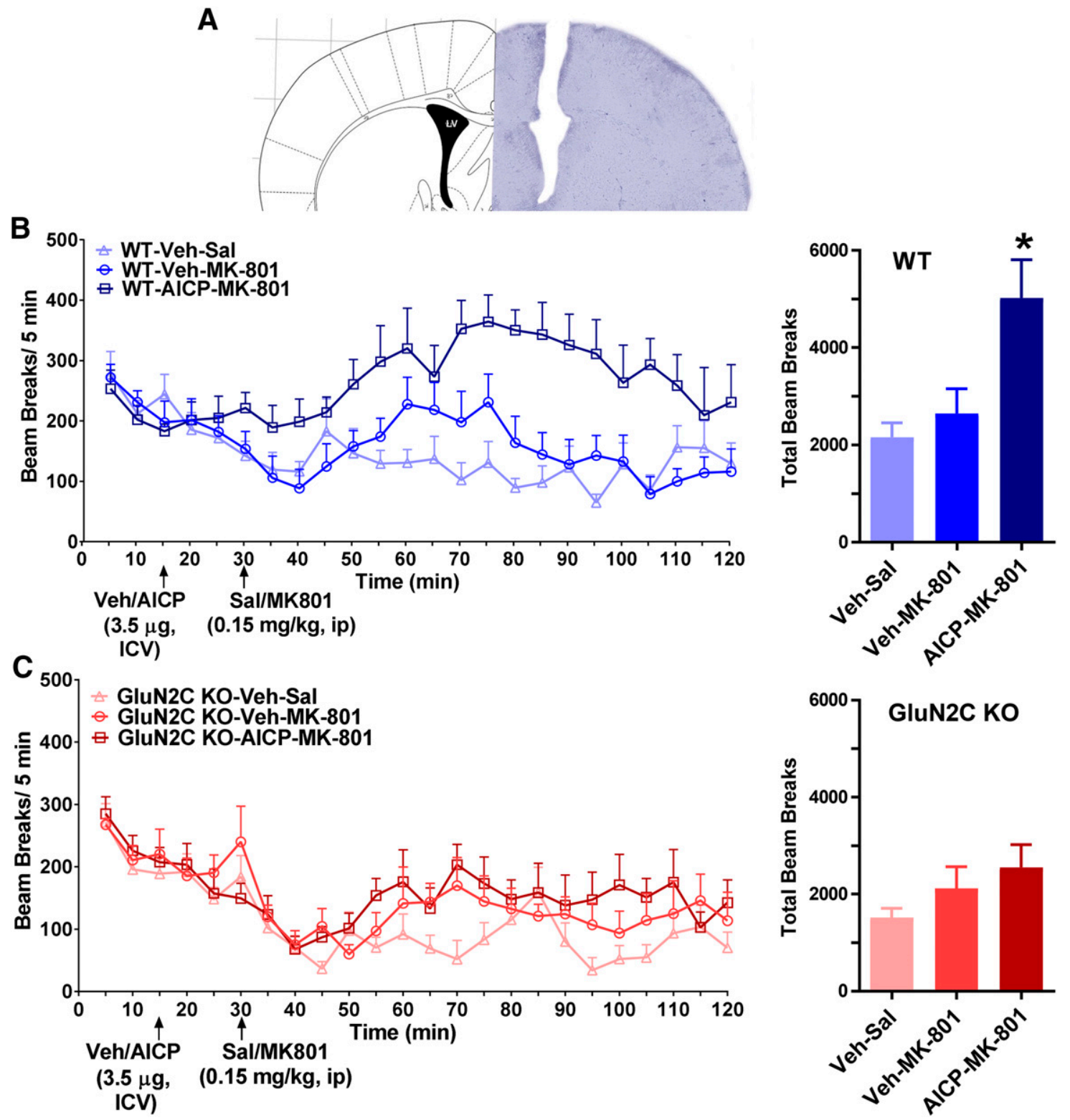

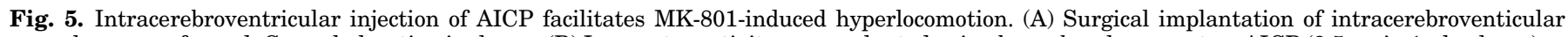

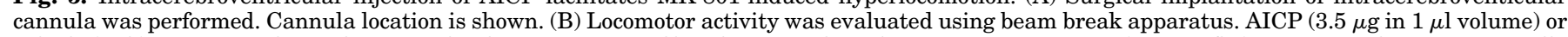

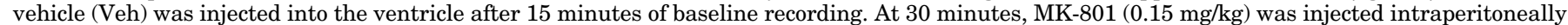

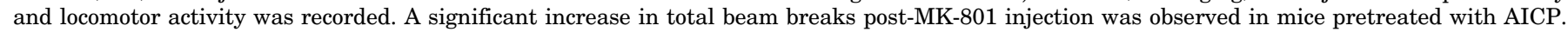

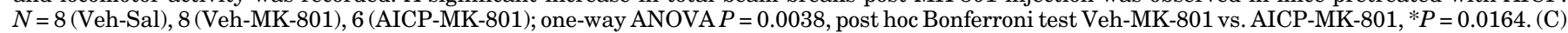

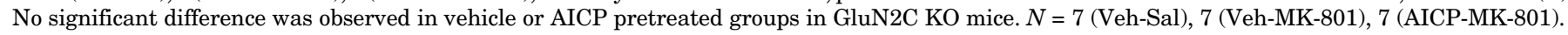


A
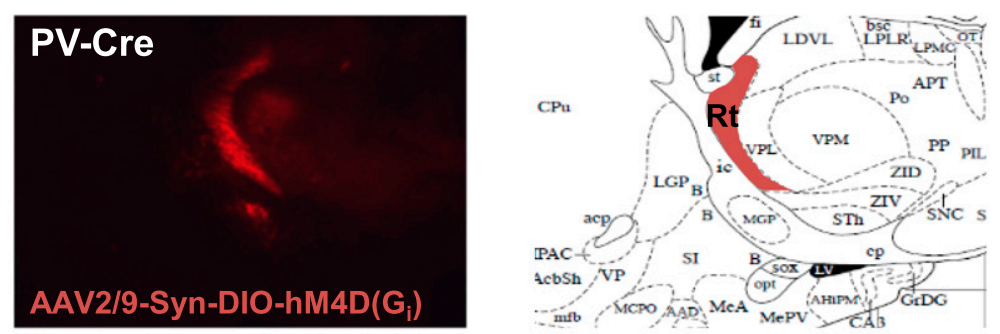

B
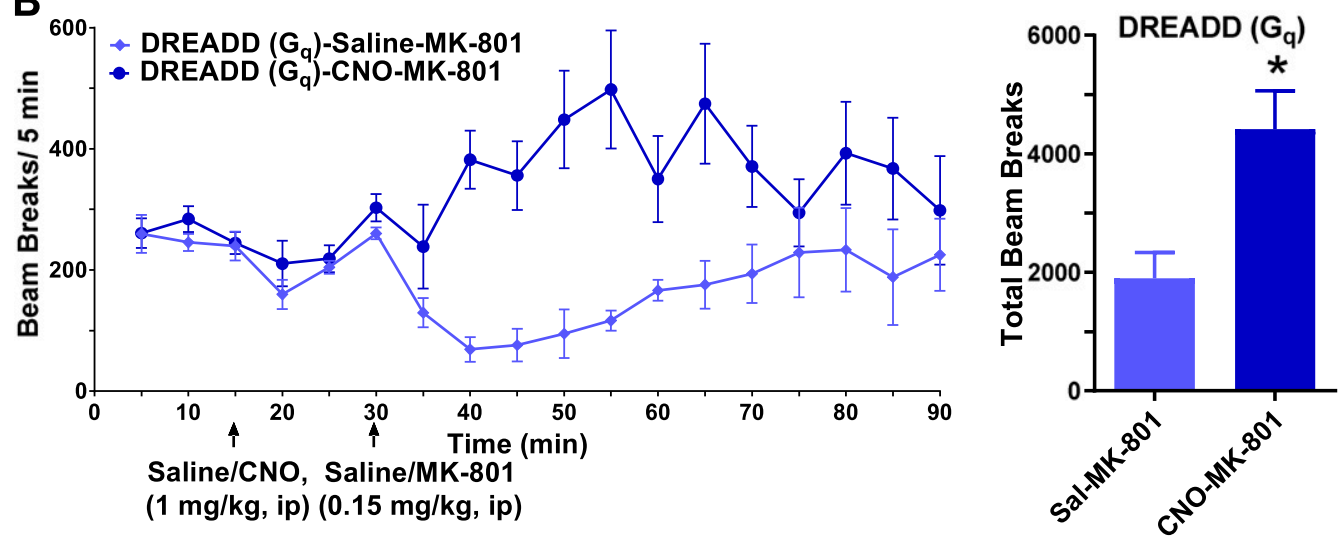

C
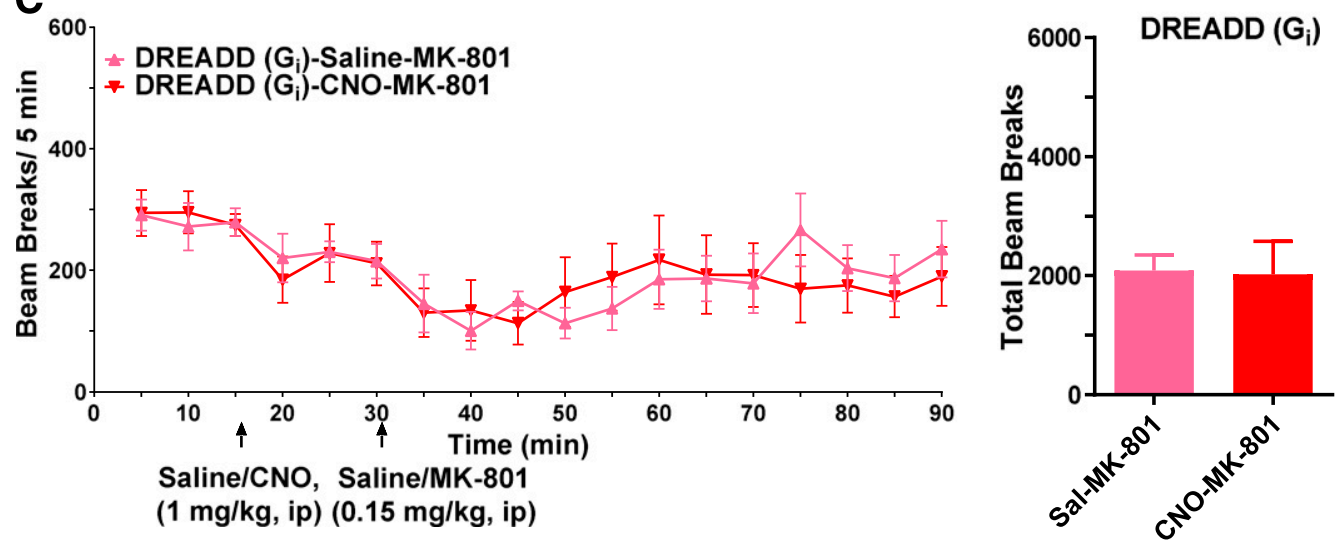

Fig. 6. Chemogenetic activation of $n R T$ neurons facilitates MK-801-induced hyperlocomotion. (A) Localization of DREADD expression in nRT. (B) $\mathrm{G}_{\mathrm{q}}$ DREADD injected animals were tested for the effect of CNO and MK-801 on locomotor activity in the beam break apparatus. After 15 minutes of baseline saline or CNO $(1 \mathrm{mg} / \mathrm{kg})$ was injected intraperitoneally. At 30 minutes, MK-801 $(0.15 \mathrm{mg} / \mathrm{kg})$ was injected intraperitoneally and locomotor activity was recorded. A significant increase in total beam breaks post-MK-801 injection was observed in mice pretreated with AICP. $N=4$ (Sal-MK-801), 6 (CNO-MK-801); unpaired $t$ test $* P=0.0217$. (C) $\mathrm{G}_{\mathrm{i}} \mathrm{DREADD}$-injected animals were tested for the effect of CNO and MK-801 on locomotor activity similar to $\mathrm{G}_{\mathrm{q}} \mathrm{DREADD}$. No significant difference was observed in animals injected with CNO or vehicle. $N=5$ (Sal-MK-801), 7 (CNO-MK-801).

ligands and are solely activated by exogenous designer drugs such as clozapine- $N$-oxide (CNO). Use of cre-lox technique further allows the selective expression of DREADD proteins in desired cells or region. Since a majority of $n R T$ neurons are PV positive, we used a PV-Cre mouse line that allows Cre recombinase expression solely in PV neurons. In the PV-Cre mouse line, we stereotaxically injected, into the $\mathrm{nRT}$ region, cre-dependent viral vectors that express activating $\left(\mathrm{G}_{\mathrm{q}}\right.$ coupled) or inhibiting $\left(\mathrm{G}_{\mathrm{i}}\right.$ coupled) DREADDs (Supplemental Fig. 2A). Using this strategy, we found that the DREADD expression was restricted to nRT region (Fig. $6 \mathrm{~A})$. After recovery from surgery and time for viral expression, behavioral studies were conducted. Modulation of DREADDs using CNO had a modest effect on basal locomotion (Supplemental Fig. 2B) and did not have significant effect on PPI or startle amplitude (Supplemental Fig. 2C). We further tested the effect of DREADD modulation on MK-801-induced locomotor activity. We found that activation of $\mathrm{G}_{\mathrm{q}} \mathrm{DREADD}$ facilitated MK-801-induced hyperlocomotion (unpaired $t$ test, $P=0.0217$; Fig. 6B). In contrast, activation of $\mathrm{G}_{\mathrm{i}} \mathrm{DREADD}$ did not have an effect on MK-801induced hyperlocomotion (Fig. 6C). Thus, both chemogenetic activation of $\mathrm{nRT}$ neurons and intracerebroventricular injection of AICP produced similar behavioral effect.

\section{Discussion}

Several key conclusions can be drawn from these studies. First, ablation of GluN2C subunit does not affect the excitability, rebound burst firing, or the resting membrane 
potential of nRT neurons. Second, in contrast to previous studies we did not find any effect of DL-AP5 on firing pattern in response to depolarizing current injection or resting membrane potential in $\mathrm{nRT}$ neurons and neither did DCS or CIQ affect these properties. We found that AICP a superagonist for GluN1/GluN2C receptors reduced the spike frequency and rebound burst and this effect was absent in GluN2C knockout mice, confirming the requirement of GluN2C subunit for this effect. We also found that AICP may produce GluN2C-selective actions in vivo and based on our analysis using a chemogenetic approach these actions appear to involve nRT neurons.

Role of NMDA Receptors in nRT Neurons. The neurons in $\mathrm{nRT}$ receive glutamatergic collaterals from cortical pyramidal neurons and thalamic relay neurons. Using pharmacological tools, it has been suggested that both thalamonRT and cortico-nRT synapses express GluN2C-containing NMDA receptors (Astori and Luthi, 2013; Fernandez et al., 2017). This finding is also supported by minimal stimulation studies that suggest the presence of NMDA receptors with lower $\mathrm{Mg}^{2+}$ sensitivity at both of these synaptic inputs onto nRT neurons (Deleuze and Huguenard, 2016). Recently it has been identified that the GluN2C-containing receptors at the cortico-nRT synapses may induce a form of plasticity that involves $\mathrm{Ca}^{2+}$ entry and facilitation of low-threshold $\mathrm{Ca}^{2+}$ channels, potentially T-type channels (Fernandez et al., 2017). However, because of the use of pharmacological agents that modulate both GluN2C- and GluN2Dcontaining receptors and lack of use of knockout approach, it is possible that some of these effects are mediated by GluN2D-containing receptors, which are also enriched in nRT neurons (Yamasaki et al., 2014; Alsaad et al., 2019). It has also been found that inhibition of NMDA receptors in $\mathrm{nRT}$ neurons resulted in delta burst firing (Zhang et al., 2009); however, we did not find this in our hands. We also did not observe any hyperpolarization by DL-AP5 or any of the other GluN2C-selective pharmacological agents. This lack of effect of DL-AP5 was observed on multiple parameter including resting membrane potential and spike frequency in both wild type and GluN2C knockout further strengthening our findings. In addition, it has been suggested that basal GluN2C-containing receptor activity may underlie the delta burst firing in response to NMDA receptor antagonist (Zhang et al., 2009), but we did not find any effect of GluN2C knockout or DCS and (+)-CIQ, which should facilitate GluN2C-containing receptors. It is possible that differences in ambient glutamate levels due to experimental conditions may account for the observed differences in the two studies.

Importantly, we found that AICP reduced the spike frequency and burst firing of nRT neurons. AICP is a newly identified glycine-site agonist of NMDA receptors with a $350 \%$ efficacy at GluN1/GluN2C NMDA receptors compared with glycine (Jessen et al., 2017). Thus, AICP affords greater efficacy compared with DCS and CIQ at GluN1/ GluN2C receptors. Modulation of $\mathrm{nRT}$ spike frequency and rebound burst firing by AICP (and not DCS and (+)-CIQ) in wild type but not in GluN2C knockout provides key information. First, GluN2C-containing receptors are basally active but possibly at a very low level to affect spike frequency or rebound burst by less efficacious drugs. This is in line with the extremely low open probability of
GluN1/GluN2C receptors in heterologous system (Dravid et al., 2008). Second, the reduction in spike frequency and rebound burst by AICP was observed in the absence of any change in membrane potential. This suggests that the observed effects of AICP are not simply due to change in threshold but possibly due to altered function of ion channels controlling these firing patterns. We did not study the mechanism of how AICP altered the excitability or rebound bursts in nRT neurons. Ion conductance via lowthreshold T-type calcium channel and calcium-activated small potassium channel (SK) are crucial for hyperpolarization induced rebound bursts in nRT neurons (Llinás and Jahnsen, 1982; Jahnsen and Llinas, 1984; Cueni et al., 2008; Clemente-Perez et al., 2017). It was previously shown that the $\mathrm{Ca}^{2+}$ influx via NMDA receptor can activate SK channels and shunt excitatory postsynaptic potential amplitude (Ngo-Anh et al., 2005; Faber, 2010; Babiec et al., 2017). In addition, NMDA receptor-mediated $\mathrm{Ca}^{2+}$ influx can lead to inactivation of T-type calcium channels (Cazade et al., 2017). Thus, it is possible that AICP-induced increase in $\mathrm{Ca}^{2+}$ influx through GluN2C-containing NMDA receptors may increase or decrease the function of SK channel or T-type calcium channel, respectively, to produce the observed effect. Further studies are required to address the potential mechanisms of AICP effect.

Role of nRT Neurons and GluN2C-Containing Receptors in Behavior and Disease. Recently, specific abnormalities in the firing of $\mathrm{nRT}$ neurons has been identified in mouse models of neurodevelopmental disorders and Dravet syndrome (Wells et al., 2016; Krol et al., 2018; Ritter-Makinson et al., 2019). In addition, extensive literature suggests a potential role of $\mathrm{nRT}$ neuron burst firing in absence seizure (Avanzini et al., 1993; Tsakiridou et al., 1995; Steriade, 2005; Paz and Huguenard, 2015, but also see Lee et al. 2014). Thus, drugs that may modulate the function of $\mathrm{nRT}$ neurons may have therapeutic use for neuropsychiatric and neurologic disorders. In addition, based on the analysis of potential mechanism of ketamine's psychotic effect and our analysis of GluN2C knockout mice, facilitation of GluN2C-containing receptors may serve as a therapeutic strategy for schizophrenia deficits (Hillman et al., 2011; Khlestova et al., 2016; Gupta et al., 2016). We found that in vivo intracerebroventricular injection of AICP did not affect basal locomotion or prepulse inhibition and startle amplitude. However, AICP facilitated MK-801-induced hyperlocomotion in wild-type but not in GluN2C knockout mice. We hypothesize that this effect of AICP may arise because of its effect on nRT neurons, because chemogenetic stimulation of nRT neurons also resulted in similar behavioral phenotype. The facilitation of MK-801-induced locomotor activity by AICP and $\mathrm{G}_{\mathrm{q}}$ DREADD may involve an enhanced channel block due to an increase in NMDA channel opening and/or relief of $\mathrm{Mg}^{2+}$-block of NMDA receptors in nRT neurons. Alternatively, AICP and MK-801 may work synergistically on parallel pathways that regulate locomotor activity. In this regard it should be noted that ablation of the obligatory GluN1 subunit from PV neurons, including those in nRT, does not impair the ability of MK-801 to induce locomotor activity or stereotypy or cortical oscillations (Bygrave et al., 2016). Overall the proof-of-principle studies suggest that AICP produces GluN2C-selective effects in vivo and 
potentially targets nRT neurons. The GluN2C subunit of the NMDA receptor exhibits a unique expression pattern. It is enriched in PV neurons in nRT, globus pallidus, and ventral pallidum and in astrocytes in much of the telencephalic nuclei (Ravikrishnan et al., 2018; Alsaad et al., 2019). Thus, drugs that can selectively modulate the activity of GluN2C-containing receptors may produce unique effects on neural circuitry. Recent studies have identified several molecules including CIQ (Mullasseril et al., 2010; Santangelo Freel et al., 2013) and PYD-106 (Khatri et al., 2014; Zimmerman et al., 2014; Bhattacharya et al., 2018), which can facilitate GluN2C-containing receptors with unique dependence on channel composition. More recently AICP and other glycine-site agonists have been identified that facilitate the function of GluN1/ GluN2C receptors (Jessen et al., 2017; Maolanon et al., 2017). Glycine-site agonists have generally been found to exhibit higher safety profile as evident from DCS. Thus, future studies to further address the GluN2C-selective effects of AICP and related compounds on neural circuits may lead to newer therapeutic avenues.

\section{Acknowledgments}

We thank Ratnamala Pavuluri, Pauravi J. Gandhi, and Anna Ayala for excellent technical help. The content is solely the responsibility of the authors. We thank the Wellcome Trust Sanger Institute Mouse Genetics Project (Sanger MGP) and its funders for providing the mutant mouse line Grin2 $\mathrm{C}^{\mathrm{tm} 1 \text { (EGFP/cre/ERT2)Wtsi. }}$. Funding and associated primary phenotypic information may be found at www.sanger.ac.uk/ mouseportal.

\section{Authorship Contributions}

Participated in research design: Liu, Shelkar, Dravid.

Conducted experiments: Liu, Shelkar.

Contributed new reagents or analytic tools: Zhao, Clausen.

Performed data analysis: Liu, Shelkar, Dravid.

Wrote or contributed to writing of the manuscript: Liu, Shelkar, Dravid.

\section{References}

Ahrens S, Jaramillo S, Yu K, Ghosh S, Hwang GR, Paik R, Lai C, He M, Huang ZJ, and Li B (2015) ErbB4 regulation of a thalamic reticular nucleus circuit for sensory selection. Nat Neurosci 18:104-111.

Alsaad HA, DeKorver NW, Mao Z, Dravid SM, Arikkath J, and Monaghan DT (2019) In the telencephalon, GluN2C NMDA receptor subunit mRNA is predominately expressed in glial cells and GluN2D mRNA in interneurons. Neurochem Res 44 61-77.

Astori S and Lüthi A (2013) Synaptic plasticity at intrathalamic connections via CaV3.3 T-type Ca2+ channels and GluN2B-containing NMDA receptors. $J$ Neurosci 33:624-630.

Avanzini G, Vergnes M, Spreafico R, and Marescaux C (1993) Calcium-dependent regulation of genetically determined spike and waves by the reticular thalamic nucleus of rats. Epilepsia 34:1-7.

Babiec WE, Jami SA, Guglietta R, Chen PB, and O’Dell TJ (2017) Differential regulation of NMDA receptor-mediated transmission by SK channels underlies dorsalventral differences in dynamics of schaffer collateral synaptic function. $J$ Neurosci 37:1950-1964.

Bhattacharya S, Khatri A, Swanger SA, DiRaddo JO, Yi F, Hansen KB, Yuan H, and Traynelis SF (2018) Triheteromeric GluN1/GluN2A/GluN2C NMDARs with unique single-channel properties are the dominant receptor population in cerebellar granule cells. Neuron 99:315-328.e5.

Buller AL, Larson HC, Schneider BE, Beaton JA, Morrisett RA, and Monaghan DT (1994) The molecular basis of NMDA receptor subtypes: native receptor diversity is predicted by subunit composition. $J$ Neurosci 14:5471-5484.

Bygrave AM, Masiulis S, Nicholson E, Berkemann M, Barkus C, Sprengel R, Harrison PJ, Kullmann DM, Bannerman DM, and Kätzel D (2016) Knockout of NMDA-receptors from parvalbumin interneurons sensitizes to schizophreniarelated deficits induced by MK-801. Transl Psychiatry 6:e778.

Cazade M, Bidaud I, Lory P, and Chemin J (2017) Activity-dependent regulation of T-type calcium channels by submembrane calcium ions. eLife $\mathbf{6}$ : e22331.

Clemente-Perez A, Makinson SR, Higashikubo B, Brovarney S, Cho FS, Urry A, Holden SS, Wimer M, Dávid C, Fenno LE, et al. (2017) Distinct thalamic reticular cell types differentially modulate normal and pathological cortical rhythms. Cell Rep 19:2130-2142.
Crick F (1984) Function of the thalamic reticular complex: the searchlight hypothesis. Proc Natl Acad Sci USA 81:4586-4590.

Cueni L, Canepari M, Luján R, Emmenegger Y, Watanabe M, Bond CT, Franken P, Adelman JP, and Lüthi A (2008) T-type Ca2+ channels, SK2 channels and SERCAs gate sleep-related oscillations in thalamic dendrites. Nat Neurosci 11: 683-692.

Deleuze C and Huguenard JR (2016) Two classes of excitatory synaptic responses in rat thalamic reticular neurons. J Neurophysiol 116:995-1011.

Dravid SM, Burger PB, Prakash A, Geballe MT, Yadav R, Le P, Vellano K, Snyder JP, and Traynelis SF (2010) Structural determinants of D-cycloserine efficacy at the NR1/NR2C NMDA receptors. $J$ Neurosci 30:2741-2754.

Dravid SM, Prakash A, and Traynelis SF (2008) Activation of recombinant NR1/ NR2C NMDA receptors. $J$ Physiol 586:4425-4439.

Faber ES (2010) Functional interplay between NMDA receptors, SK channels and voltage-gated $\mathrm{Ca} 2+$ channels regulates synaptic excitability in the medial prefrontal cortex. J Physiol 588:1281-1292.

Fernandez LMJ, Pellegrini C, Vantomme G, Béard E, Lüthi A, and Astori S (2017) Cortical afferents onto the nucleus Reticularis thalami promote plasticity of lowthreshold excitability through GluN2C-NMDARs. Sci Rep 7:12271.

Gentet LJ and Ulrich D (2003) Strong, reliable and precise synaptic connections between thalamic relay cells and neurones of the nucleus reticularis in juvenile rats. J Physiol 546:801-811.

Gupta SC, Ravikrishnan A, Liu J, Mao Z, Pavuluri R, Hillman BG, Gandhi PJ, Stairs DJ, Li M, Ugale RR, et al. (2016) The NMDA receptor GluN2C subunit controls cortical excitatory-inhibitory balance, neuronal oscillations and cognitive function. Sci Rep 6:38321.

Gupta SC, Yadav R, Pavuluri R, Morley BJ, Stairs DJ, and Dravid SM (2015) Essential role of GluD1 in dendritic spine development and GluN2B to GluN2A NMDAR subunit switch in the cortex and hippocampus reveals ability of GluN2B inhibition in correcting hyperconnectivity. Neuropharmacology 93:274-284.

Halassa MM and Kastner S (2017) Thalamic functions in distributed cognitive control. Nat Neurosci 20:1669-1679.

Hillman BG, Gupta SC, Stairs DJ, Buonanno A, and Dravid SM (2011) Behavioral analysis of NR2C knockout mouse reveals deficit in acquisition of conditioned fear and working memory. Neurobiol Learn Mem 95:404-414.

Huguenard JR (1998) Anatomical and physiological considerations in thalamic rhythm generation. J Sleep Res 7 (Suppl 1):24-29.

Huguenard JR and McCormick DA (2007) Thalamic synchrony and dynamic regulation of global forebrain oscillations. Trends Neurosci 30:350-356.

Jahnsen H and Llinás R (1984) Ionic basis for the electro-responsiveness and oscillatory properties of guinea-pig thalamic neurones in vitro. $J$ Physiol $\mathbf{3 4 9}$ : $227-247$

Jessen M, Frederiksen K, Yi F, Clausen RP, Hansen KB, Bräuner-Osborne H, Kilburn P, and Damholt A (2017) Identification of AICP as a GluN2C-selective $\mathrm{N}$-methyl-d-aspartate receptor superagonist at the GluN1 glycine site. Mol Pharmacol 92:151-161.

Khatri A, Burger PB, Swanger SA, Hansen KB, Zimmerman S, Karakas E, Liotta DC, Furukawa H, Snyder JP, and Traynelis SF (2014) Structural determinants and mechanism of action of a GluN2C-selective NMDA receptor positive allosteric modulator. Mol Pharmacol 86:548-560.

Khlestova E, Johnson JW, Krystal JH, and Lisman J (2016) The role of GluN2Ccontaining NMDA receptors in ketamine's psychotogenic action and in schizophrenia models. J Neurosci 36:11151-11157.

Krol A, Wimmer RD, Halassa MM, and Feng G (2018) Thalamic reticular dysfunction as a circuit endophenotype in neurodevelopmental disorders. Neuron 98:282-295.

Lam YW and Sherman SM (2011) Functional organization of the thalamic input to the thalamic reticular nucleus. $J$ Neurosci 31:6791-6799.

Lam YW and Sherman SM (2010) Functional organization of the somatosensory cortical layer 6 feedback to the thalamus. Cereb Cortex 20:13-24.

Lee SE, Lee J, Latchoumane C, Lee B, Oh SJ, Saud ZA, Park C, Sun N, Cheong E, Chen CC, et al. (2014) Rebound burst firing in the reticular thalamus is not essential for pharmacological absence seizures in mice. Proc Natl Acad Sci USA 111: 11828-11833.

Lin YJ, Bovetto S, Carver JM, and Giordano T (1996) Cloning of the cDNA for the human NMDA receptor NR2C subunit and its expression in the central nervous system and periphery. Brain Res Mol Brain Res 43:57-64.

Llinás R and Jahnsen H (1982) Electrophysiology of mammalian thalamic neurones in vitro. Nature 297:406-408.

Llinás RR and Steriade M (2006) Bursting of thalamic neurons and states of vigilance. J Neurophysiol 95:3297-3308.

Lüthi A (2014) Sleep spindles: where they come from, what they do. Neuroscientist 20:243-256.

Maolanon AR, Risgaard R, Wang SY, Snoep Y, Papangelis A, Yi F, Holley D, Barslund AF, Svenstrup N, Hansen KB, et al. (2017) Subtype-specific agonists for NMDA receptor glycine binding sites. ACS Chem Neurosci 8:1681-1687.

Marlinski V, Sirota MG, and Beloozerova IN (2012) Differential gating of thalamocortical signals by reticular nucleus of thalamus during locomotion. J Neurosci 32 : 15823-15836.

Monyer H, Burnashev N, Laurie DJ, Sakmann B, and Seeburg PH (1994) Developmental and regional expression in the rat brain and functional properties of four NMDA receptors. Neuron 12:529-540.

Mullasseril P, Hansen KB, Vance KM, Ogden KK, Yuan H, Kurtkaya NL, Santangelo R, Orr AG, Le P, Vellano KM, et al. (2010) A subunit-selective potentiator of NR2Cand NR2D-containing NMDA receptors. Nat Commun 1:90.

Nair A, Treiber JM, Shukla DK, Shih P, and Müller RA (2013) Impaired thalamocortical connectivity in autism spectrum disorder: a study of functional and anatomical connectivity. Brain 136:1942-1955.

Ngo-Anh TJ, Bloodgood BL, Lin M, Sabatini BL, Maylie J, and Adelman JP (2005) SK channels and NMDA receptors form a $\mathrm{Ca} 2+$-mediated feedback loop in dendritic spines. Nat Neurosci 8:642-649. 
Paz JT and Huguenard JR (2015) Microcircuits and their interactions in epilepsy: is the focus out of focus? Nat Neurosci 18:351-359.

Ravikrishnan A, Gandhi PJ, Shelkar GP, Liu J, Pavuluri R, and Dravid SM (2018) Region-specific expression of NMDA receptor GluN2C subunit in parvalbuminpositive neurons and astrocytes: analysis of GluN2C expression using a novel reporter model. Neuroscience 380:49-62.

Ritter-Makinson S, Clemente-Perez A, Higashikubo B, Cho FS, Holden SS, Bennett E, Chkhaidze A, Eelkman Rooda OHJ, Cornet MC, Hoebeek FE, et al. (2019) Augmented reticular thalamic bursting and seizures in Scn1a-dravet syndrome [published correction appears in Cell Rep (2019) 26:1071]. Cell Rep 26:54-64.e6.

Santangelo Freel RM, Ogden KK, Strong KL, Khatri A, Chepiga KM, Jensen HS, Traynelis SF, and Liotta DC (2013) Synthesis and structure activity relationship of tetrahydroisoquinoline-based potentiators of GluN2C and GluN2D containing N-methyl-D-aspartate receptors. J Med Chem 56:5351-5381.

Sheinin A, Shavit S, and Benveniste M (2001) Subunit specificity and mechanism of action of NMDA partial agonist D-cycloserine. Neuropharmacology 41:151-158.

Sherman SM (2007) The thalamus is more than just a relay. Curr Opin Neurobiol 17: 417-422.

Steriade M (2005) Sleep, epilepsy and thalamic reticular inhibitory neurons. Trends Neurosci 28:317-324.

Traynelis SF, Wollmuth LP, McBain CJ, Menniti FS, Vance KM, Ogden KK, Hansen KB, Yuan H, Myers SJ, and Dingledine R (2010) Glutamate receptor ion channels: structure, regulation, and function. Pharmacol Rev 62:405-496.

Tsakiridou E, Bertollini L, de Curtis M, Avanzini G, and Pape HC (1995) Selective increase in T-type calcium conductance of reticular thalamic neurons in a rat model of absence epilepsy. J Neurosci 15:3110-3117.

Urwyler S, Floersheim P, Roy BL, and Koller M (2009) Drug design, in vitro pharmacology, and structure-activity relationships of 3 -acylamino-2-aminopropionic acid derivatives, a novel class of partial agonists at the glycine site on the N-methyl-D-aspartate (NMDA) receptor complex. J Med Chem 52:5093-5107.

von Krosigk M, Bal T, and McCormick DA (1993) Cellular mechanisms of a synchronized oscillation in the thalamus. Science 261:361-364.

Watanabe M, Inoue Y, Sakimura K, and Mishina M (1992) Developmental changes in distribution of NMDA receptor channel subunit mRNAs. Neuroreport 3:1138-1140.
Wells MF, Wimmer RD, Schmitt LI, Feng G, and Halassa MM (2016) Thalamic reticular impairment underlies attention deficit in Ptchd1(Y/-) mice. Nature 532: $58-63$.

Wenzel A, Fritschy JM, Mohler H, and Benke D (1997) NMDA receptor heterogeneity during postnatal development of the rat brain: differential expression of the NR2A, NR2B, and NR2C subunit proteins. $J$ Neurochem 68:469-478.

Woodward ND, Giraldo-Chica M, Rogers B, and Cascio CJ (2017) Thalamocortical dysconnectivity in autism spectrum disorder: an analysis of the Autism Brain Imaging Data Exchange. Biol Psychiatry Cogn Neurosci Neuroimaging 2:76-84.

Yadav R, Gupta SC, Hillman BG, Bhatt JM, Stairs DJ, and Dravid SM (2012) Deletion of glutamate delta-1 receptor in mouse leads to aberrant emotional and social behaviors. PLoS One 7:e32969.

Yamasaki M, Okada R, Takasaki C, Toki S, Fukaya M, Natsume R, Sakimura K, Mishina M, Shirakawa T, and Watanabe M (2014) Opposing role of NMDA receptor GluN2B and GluN2D in somatosensory development and maturation. J Neurosci 34:11534-11548.

Zhang Y, Buonanno A, Vertes RP, Hoover WB, and Lisman JE (2012) NR2C in the thalamic reticular nucleus; effects of the NR2C knockout. PLoS One 7:e41908.

Zhang Y, Llinas RR, and Lisman JE (2009) Inhibition of NMDARs in the nucleus reticularis of the thalamus produces delta frequency bursting. Front Neural Circuits 3:20.

Zikopoulos B and Barbas H (2006) Prefrontal projections to the thalamic reticular nucleus form a unique circuit for attentional mechanisms. $J$ Neurosci 26 7348-7361

Zimmerman SS, Khatri A, Garnier-Amblard EC, Mullasseril P, Kurtkaya NL, Gyoneva S, Hansen KB, Traynelis SF, and Liotta DC (2014) Design, synthesis, and structure-activity relationship of a novel series of GluN2C-selective potentiators. J Med Chem 57:2334-2356.

Address correspondence to: Shashank M. Dravid, Department of Pharmacology and Neuroscience, School of Medicine, Creighton University, $2500 \mathrm{Cal}-$ ifornia Plaza, Omaha, NE 68178. E-mail: shashankdravid@creighton.edu 